\title{
Popularity of Vampire Fiction among Teenage Masses
}

\author{
Debangana Basu
}

Department of English, Amity University, Kolkata, India

\begin{abstract}
The purpose of this research is to show the amount of obsession of the teenagers, especially the teen girls on vampire fiction. It is also the purpose to find out the reason of this obsession and what effects do it have on the lives of the teenagers. In today's world, where culture is changing rapidly and people are demanding newer things to read, the writers now rolling their sleeves up and are exploring newer areas, rejuvenating the older folkloric traditions. The effects are very visible as these topics of exploration are being readily accepted and the teens especially are responding to these works very actively. It is taking a great toll on the minds of the teenagers and they are craving more of it.
\end{abstract}

Keywords-Vampire Fiction, Teenage.

\section{INTRODUCTION}

Culture varies from place to place and each culture has its own flavour. Such is the popular culture of vampire fiction which has gained immense popularity in the field of literature in abroad. As the title of my project suggests, I will be dealing with the issue of the towering popularity of vampire fiction among the teenage people, not just based in abroad, but also its budding interest and its spread among the Indian teenage masses also. It has been quite a huge topic of discussion since time immemorial. Vampire fiction has evolved in full fledge and gaining a permanent place gradually in modern literature. Teenage is a growing period of the minds and hearts of individuals and at this point of stage they start fantasizing, especially girls, about their knight in shining armour, who would be incredibly handsome, powerful enough to protect her from all evils and "vampire", in modern culture seems to serve all their criteria. Therefore, the popularity of vampires in modern culture is very much relevant.

Several studies have been done regarding this subject matter and I have chosen this topic due to the fact that it is all the more appealing and is not so much popular among the Indian people, who have been only acquainted with these since few years. "The Vampyre", was first published in 1819 anonymously, followed by "Dracula" by Bram Stroker. Many researches have been done as well about these bloodsuckers. One such research has been done by John Edgar Browning of Georgia Institute of Technology. If myths are to be believes $17^{\text {th }}$ and $18^{\text {th }}$ century village society was also infested with real vampires. Recent researches have showed that, the myth of vampire has become very much popular and has got hold of a very strong position in modern literature.

To make my thesis more justifiable, I have resorted to three kinds of theory: the cultural and the reader response theory. As methodology, I have referred some articles from the web as well as from some books.

The aim of this thesis is to show the growth of the vampire issue and how it has spread its tentacles inside the head of the teenagers and how much they are obsessive about vampires. My purpose of this research will be to show through three different novels, namely "The Twilight saga", "The Vampire Diaries" and "Dead Beautiful", that how in these three fictions, the idea of the vampires shifts and change.

The thesis is divided into three chapters, dealing with three novels and the discussion about the various reasons because of which the vampire fiction is so huge among the teenage masses.

\section{POPULARITY OF VAMPIRE FICTION - THE CULTURAL EVOLUTION}

There is a very thin line like difference between fantasy and horror. Horror, as we all know, essentially deals with all the gruesome and bloody as well as the supernatural incidents; whereas, fantasy can be both like a fairytale story or something horrific other-worldly things. Such a kind of culture had started to be cultivated in literature since the late 1800 s which started dealing with all kinds of horrific incidents as well as characters whom people could only fantasize about - the vampires. Originally, when Bram Stoker had first published his novel "Dracula", people had originally developed the concept of vampires as something who were savage, animalistic and bloodsuckers. To sum up all their characteristics, they were typically the monsters, whose only motive was to suck blood from the humans and looked like walking corpse with pale skin and sharp pointed canines. Stoker, had essentially made his anti-heroes (vampires), as seductive as well as corrupt with superhuman powers and immortality. "Dracula" is widely different from what we understand by vampires today or what we read about them nowadays. Modern vampire fiction has nothing to 
do with folklore and no longer belongs to the genre of horror; rather it has become a modern fantasy where we find some new and interesting theories about the night creatures. In "Dracula", the Count had been depicted as a terrifying personality with cruel looks and sharp teeth, overall very much menacing. But today's version of vampire, as we see in Stephanie Meyer's “Twilight" saga, people, especially the teenage girls, seem to drool over the protagonist vampire Edward Cullen. Another new aspect comes under the light of consideration that, here in the novel "Twilight", the vampire Edward, does not survive on human blood; rather he and his family are in the town to protect humans from getting slaughtered by the other bloodsuckers. They survive on the animal blood and call themselves 'vegetarians'. Edward's beauty is incomparable as he is perfect in every way - his modest behaviour, his perfect chiseled looks and his unconditional love for his human mate Isabella (Bella) Swan.

Applying the two prominent theories in literature, namely the cultural and the reader-response theories, we will try to see how these modern-day vampire fictions and their heroic characters are taking a toll on the minds of the teenage people, especially the girls and why they are so obsessed with the idea of vampires. Teenage is a period of growing minds and hearts of different individuals and during this age, they grow some kind of unknown fascination for the fantasy world. In the modern day, they are obsessed with vampires. Edward Cullen, is that dreamy guy whom every girl desires, despite the fact that he is also the harbinger of death. Nobody under the sun ever wants to die, and this thing is the only wish in a teen's life and that is why most of the girls want to be bitten once by Edward after reading the novel to attain an immortal and young life.

"Cultural studies" are devoted to the analysis and interpretation of objects and social practices and we will see how, from Bram Stoker's "Dracula", to the three novels which are going to be discussed here - "Twilight saga", "The Vampire Diaries" and "Dead Beautiful", the cultural interpretation of vampires has changed. Also, according to the reader response theory, "a text has no meaning before a reader experiences or reads it" and a text may have many alternate meanings. The abovementioned texts will show that aspect too, from the following three chapters.

\section{TEENAGE OBSESSION WITH "TWILIGHT"}

As it is already talked about, the way in which we portray vampires today has changed over the centuries and nowadays, if someone utters the word 'vampire', people do not think of them as a menacing, cruel, bloodsucking creature; the image of one very popular guy comes instantly on their minds; that is, Edward Cullen from the book "Twilight". Such an impression these modern-day culture vampires have created, that it has instilled in the minds of the teenage people like a nail hammered inside a wall. They are obsessed, they daydream and they all the time fantasize about having a vampire partner instead of a prince charming or a princess, which teens usually do. Once, Stoker's "Dracula", was a sensation among the readers and now, Meyer's "Twilight" has become the source of fascination.

Basically, according to me, because of the three main reasons the teenagers are so much obsessed with vampires: they are in love with the idea of mystery and all the supernaturalthings and they want to move in a fantasy world where everything will be like a fairytale, with a "happily ever after". Also, they just want to escape from the real, mundane, boring and complicated life, because at this point of their life, they want to experience new things. Secondly, the idea of dark romance excites them. They are completely in awe with the idea that someone who would be tall, dark and incredibly handsome would be in their life and would be romantically involved with them; who would always protect them and would take on different, new and exciting adventures. And the most important thing, they want to have a grip upon during this particular age is, power - power over almost everything; be it over their parents, in the friend circle and power to take decisions. Levi Strauss had himself said that, nature is universal and spontaneous and it does not belong to any culture or any determinate norms. Now, it can be so that, by the term 'nature', he meant the characteristics of different individuals. The culture may be different of Indians, Americans and many others but the nature of the teenagers are almost the same everywhere. The Indian teens came into contact with the idea of vampires much later than any foreign teenagers did, especially in U.S. but the effect it had on them is probably the same. Now, the teens of India are also equally obsessed with vampires, and essentially Edward from "Twilight", Stefan and Damon from "The Vampire Diaries", have become a household name.

Coming back to "Twilight" and why has it influenced the teens so much, has been vaguely discussed by the three common characteristics which have been mentioned earlier, but it needs a lot more specific explanation to justify the reasons properly. All the three series of this novel have sold 220 million copies and the movies which were made based on these novels, have grossed over $\$ 2$ billion worldwide. A short summary of this novel is necessary, to deal with the reason of the obsession. So, basically the novel talks about a small-town girl called Bella, who comes to Forks for continuing her studies due 
to family issues. There she meets a coven of vampire and specifically, one member of the family strikes her in one shot, whose name is Edward Cullen, and is strikingly handsome and appealing at the same time and eventually she falls for him, later knowing the fact that he is a vampire. Even after knowing this, her feelings for Edward does not change and they both fall in love with each other. So, the lion too fell in love with the lamb and they continued facing many obstacles but eventually they eradicated them and led a happy life. In this novel, mention of werewolves have also been made and Jacob, the other male protagonist, is a werewolf and plays a very important part but since the theme is on vampires only, the werewolves would be brought in for references. In this novel, some very striking things happen which influence and excite the teenage readers very much. Bella, falls in love with Edward who is a "good" vampire and does not harm the humans and survives on animal blood. This is a very good reason, for which the teenage girls fall instantly in love with Edward though he is a vampire because here, he is a saviour; he protects the lives of humans and that is the thing which a girl seeks as one of the qualities in their partners; that they would be goodwilled and caring by heart. Bella also befriends Jacob, a werewolf, who falls for her but Bella however marries Edward, expects a baby with him too, who would be half human and half vampire; again, this exciting and thrilling idea appeals the teens; when almost Bella is on the verge of death during the delivery, Edward changes her into a vampire. This transformation of Bella, achieving immortality, becoming incredibly beautiful and gaining immense power is another main reason because of which the teens are tempted. Some people credit Meyer's style of writing which is descriptive with alluring characters and some others point out Edward's romantic charm and appreciates his old-fashioned nature, his respectful and protective ways towards Bella and his idea of keeping Bella chaste till marriage.

Teenagers, are generally very much inexperienced in love and they sometimes tend to idolize the opposite sex. A teenage girl might think that boys are more experienced than them and they feel intrigued by this fact and feel insecure. Teenage boys also sometime think that girls are more experienced and is great at toying with their feelings. So, that is why it is understandable that why are teens are attracted towards Edward and Jacob in the case of girls and Bella in case of boys. In the novels, Jacob loves Bella so much that he never gives up on her, even after she rejects; though at the end, their relationship change drastically. However, to talk about a guy, who is of sixteen or seventeen years of age, has never had a girlfriend before, his unattached behaviour as well as his straight forward attitude and physical advances would be very much unlikely in real life. "Both Edward and Jacob's self-assured behaviour also saves Bella the trouble of taking the first steps in their relationship which, to a young girl, would be a very intimidating thing, and also something she might automatically expect guys to take care of.

Many teenage girls feel that they are not good enough for anybody and feels at times lonely, left out, ugly and unlovable. Their self-esteem kind of lowers down and they feel that they are just "normal" and no hot and handsome hunk can fall in love with them as they are not that special and not a "knock-you-dead" beauty. They may consider themselves intelligent enough but they know they are no Einstein. Added to all these, if they find themselves clumsy then that is the end of their selfconfidence. This is the description of more or less of $75 \%$ of the population. Bella, though confident and pretty, possesses all these above characteristics; but everything changes when Edward Cullen walks into her life and finds the "normal" Bella very special and falls for her. Well, the kind of adoration, love, unfathomable devotion is indeed irrational in the real world, as that much perfection can be seen nowhere in a guy. But for the food of imagination of the teenagers, after seeing Edward, they feel that such guys do exist and that is where they get delusional. Edward is that perfect 'boyfriend material', who is immortal, smart, hot, rich and compassionate. A fantasy as it is, it creates a perfect imaginative world for the teens as they are not mature enough or experienced enough to know that this kind of world or this sort of perfection does not exist. After reading these books, they, though, for a short period of time can pretend to think that real life Edward exists; which is mere escapism. The love between Edward and Bella is no ordinary love, it is a crazy one. For example, Edward watches Bella sleep the whole night every day, he tries to commit suicide when he hears the fake news of Bella's death and struggles with jealousy when she gets close to Jacob. These typical boyfriend features if one experiences in real life, a girl will go mad as it is not normal; but for the teens, these are magical and they crave for someone like this. Again, immortality is another factor which everyone craves but this craving is more dominant among the teens. They never want to age and want to remain forever beautiful and handsome; this brings out their love for Edward and Bella more because of their immortality. Basically, perfection resides in this series. Therefore, being the most important, sensational and contemporary vampire novel, which the teens of India as well as abroad come in contact with, Meyer's "Twilight" is of great importance. It has somewhat become a cultural phenomenon and if we look at it from today's point of view, it is really relevant with the demands and fantasies of teens, no matter from 
whatever culture they belong. Though some of them have got the taste of it later, but the effect is still very much the same on them. For any text, the response of a reader is very important otherwise, the text would not have any meaning. Stanley Fish has said that "the focus of readerresponse theory is to include the validity and significance of interpretations guided by the environments or communities inhabited by the readers." Here, according to the culture of U.S. the concept of vampirism and supernatural creatures and elements are very much common but for the Indian people, and as per their communities and environments, it would take time to understand and interpret these things and in the process, get entangled in the web of these ideas. Eventually it happened and the effect is almost the same though the level of craze might vary.

\section{THE OBSESSION INCREASES MORE WITH L.J. SMITH'S “THE VAMPIRE DIARIES"}

New born vampires really do have some issues with controlling blood thirst and it is very much evident in L.J. Smith's famous vampire series, "The Vampire Diaries". Smith is an American bestselling author of many children as well as adult novels. Now here is a twist to this story and it is a lot different from the novel "Twilight"; while in "Twilight", there were only one hero and heroine, in "Vampire Diaries", there are two heroes and one heroine. Stefan and Damon Salvatore are two brothers who captures a sweet and petite human, Elena Gilbert's heart. Vampires are bad and gruesome, it was a fact well known since Stoker's "Dracula "and later the notion got broken by Meyer's "Twilight" saga. In "Vampire Diaries", there are to be found a mixture of two types of vampires - a good one and a bad one. Basically, in this series there is a mixture of the "old" and the "new" vampire; that is, a mixture of both "Dracula" and "Twilight". Stefan Salvatore represents the "new" vampire with all the good attributes like Edward and Damon Salvatore represents the "old" bad vampire who is all about evil.

The meeting of Stefan and Elena is such that it would take only a second for the teens to swoon as it was that much romantic and mysterious at the same time. The idea of solitariness, isolation also intrigues the teens and they find it really fascinating that Stefan who had led a solitary life before coming to Fell's Church, is now ready to take up a normal life by attending high school and mingling with people. Like Edward Cullen he too feeds from animals and very rarely kills them altogether. During teenage, girls and boys suffer from unrequited love and also suffer from that shyness due to which they sacrifice their love sometimes. Here, Stefan, in order to protect Elena from himself only, tries to stay away from her as he might not control his thirst for human blood but ultimately fails to do so as ultimately love demolishes all hurdles. This idea of love conquers in the end, instigates a certain kind of hope in the hearts of the teens that they could also find their true love and achieve their romantic "forever". Obviously, the sweet looks of Stefan are also another cause because of which the teens drool. Eventually his brother Damon, comes in the town and starts creating havoc by creating massacre, drinking human blood and killing people. He manipulates Stefan in such a way that he almost believes that he is causing all these things and questions his sanity. This high voltage drama is loved and enjoyed by the teens very much and they hang on impatiently to what unfolds next. The extra drama is added when a doppelganger is introduced of Elena, who is Katherine Pierce and happens to be Stefan's ex-girlfriend.

Robert Pattinson as Edward Cullen and Paul Wesley as Stefan Salvatore has managed to pull off that hard-to-getover charm and dazed all the girls especially the teens, still there are some girls who prefer bad boys too and Ian Somerhalder as Damon Salvatore, has filled that gap. He is a bad boy extraordinaire who makes all the bad decisions, all the bad deeds he does but still under the magical spell of Elena's love, he redeems himself and falls in love with her and eventually Elena does too, ending things with Stefan. Well, somebody will call it fickleness but others will feel that it's just the way it is sometimes it is just all about the person with whom it clicks and we will feel our souls connected to them; and this happens with the teenagers too. Break-ups, multiple relationships are all common among the teens and they use their loneliness as imagination, when they escape to find this kind of a perfect world. Friendship is something which matters to the teens a lot as they make among themselves lots of promises to stay together and some set perfect examples of it. A kind of friendship is shown in "Twilight", where Bella and Jacob share a sweet relation of friendship but the fact that he is head over heels in love with Bella, mars their friendship and becomes a kind of different relation in the end. On the other hand, in "Vampire Diaries", we get to see a how much strong the friendship is between Elena, Caroline and Bonnie. Despite the ongoing entering of various supernatural forces, their friendship remains unharmed and where it is a popular saying that girls cannot be best friends as some sort of jealousy always works, these three have proven the notion wrong and has set an example. This thing gives the teenage girls and boys a great amount of positivity, that they can also establish this kind of friendship, and trust each other blindly which sometimes gives a friend for life or a lesson for life; the teens love to explore these kinds of dramatic friendships in their lives. Here, a huge 
cultural difference comes. In U.S. if a girl and a boy breaks up, and after sometime that girl's best friend starts liking that guy then she directly tells her, confirms the fact that they are over their relationship or not and then starts dating that guy, which too is a normal thing for the former girl also. But, in India, if any such thing happens, the best friends can become strangers in a minute. So, after reading these novels, the teens of U.S. or any other country will feel very much comfortable, as it is very much normal there, the Indian teens, even if by a slightest moment, will feel awkward about it, and it is not their fault; the culture has made them think like that.

Now, comes a very interesting part, and which has not been included in any vampire novels till "Vampire Diaries" happened. These are the race of beings, who have never been seen in either "Dracula" or "Twilight". Where the "Twilight" vampires have powers of carrying out conversations through telepathy, here in the "Vampire Diaries", this power has been given to the 'witches'. For the first time, the witches are included in a vampire series. Magical spells, indomitable power aid them in their work. Bonnie, one of Elena's best friends, is a psychic, as well as a witch who can take down any weak vampire by giving them killing migraines and in the process, defeat them. This is a fact which gives an added interest to the teens as, as it is they are very much obsessed with powers which they are getting to experience from the vampires and if magical spells be included then nothing will be of so much importance to them than this; because, magic is something which is of great interest to them as they want magic to happen in every sphere of their life. Though here, magic is used both in a good and bad way, but either way, it excites the teenagers. This series of vampire fiction, as I feel is a great move from horror to fantasy and runs on a different format. L.J. Smith, wanted to include his own ideas about vampires and deviates from the conventional terms and conditions of portraying a vampire. People have already read about the conventional nature of the vampires and when they read "Vampire Diaries", they feel that they are getting to explore a new area of the vampire fiction altogether. We can see this novel from a different angle. This novel features boarding schools which are located outside the city and the vampires come there as students and study there. The only adults who are around them are their teachers and their guardians. This indicates that they have some sort of freedom from their constant parental supervision and they become independent too, in the process. They, as a result, have to rely on them only to solve all their problems which they love to and want to do. This is wanted by all the teenagers. At a certain point of their age, they want to explore things, make decisions, be it good or bad, make mistakes and solve their own problems. This gives them a sense of freedom and encourages them to tackle their problems in their own way. So, this is another reason for which they love these kinds of novels. Good vs evil is also another factor which interests the teens very much. Villainy will be there and then the hero or the heroine will emerge. In "Vampire Diaries", Katherine is a doppelganger of Elena and is a hardcore villain and so is Klaus. The interest of the teens lie in the fact that how these two would be defeated by the good boy Stefan and the bad boy Damon (who also, changes because of Elena's love); and above all both the brothers want to protect Elena. Teen girls love bad boys too and here, though Damon is a devil incarnate, he too has a soft side which he does not show but he admits his love for Elena and does everything to protect her from all sorts of dangers. Another fact is very interesting is that, Elena is nothing like Bella. Where Bella was a soft, timid sort of a person and would let Edward, Jacob and her father make all the decisions for her, Elena on the other hand is not a "spineless, swooning damsel-in-distress". She is ballsy enough to stand up for her friends and herself but she just faces a small problem or rather a dilemma - whom to choose.

Therefore, in this novel, there is everything which "Twilight" somewhat lacks according to me. There is an eternal bond of friendship, complex relationships, hardcore love, witches' spells, villainy, horror, fantasy, etc. Overall, this is a compact example of vampire fiction where there is a perfect balance between the "old" and the "new" vampire.

\section{YVONNE WOON'S UNIQUE "DEAD BEAUTIFUL"}

"Dead Beautiful" by Yvonne Woon, an U.S. based writer, is like "Twilight" and "Vampire Diaries", an urban fantasy but the characteristics of the vampires or the 'undead' as it is called here in this book, are not the same as those of the afore mentioned novels. Rather, they are completely different and it is a complete different take on the vampires. Renée Winters, one of the protagonist of this story becomes an orphan when she loses both of her parents in a mysterious accident. She founds them inside the woods where she is being taken through some mysterious compulsion; as if someone wanted her to lead to her parents and there she finds them - "...my mother had looked inexplicably older than she had the day before." Again, her grandfather when comes tell her that, "Your parents died. I don't know why or how or by whom, but it certainly was not by natural causes". Both of her parents were discovered gauze stuffed in their mouths but no physical injuries were not there. Later, she gets transferred to a boarding school, called "Gottfried Academy" where she tries to adjust with her new life and 
new conventional and ancient subjects like Latin and others. There is where she meets the mysterious, incredibly handsome Dante, for whom she is attracted all at once, typically smitten like Bella was by Edward. So, their meeting was almost the same but the circumstances led thereafter was completely different. The characteristics of a typical vampire though maybe present but not fully. Dante is an undead but his life span is limited as he is about to die after a certain period of time and he can only be immortal, if he kisses a human girl and takes her soul away from her. As the teens want to meet their prince charming, under dramatic circumstances and want their love story to go on dramatically, the same thing happens with Renée and Dante. They just love what unfolds next as both these lovers fight with all the obstacles that life put forth and finally overcomes them and confesses their love for each other. But problems do not end there because continuous disappearances and deaths start happening. Renée's best friend Eleanor goes missing and ultimately, she has been found but not as a human but as a vampire; as an undead. Intriguing and interesting is the fact to the readers especially the teens that this storyline keeps them glued up as they can't wait to see what drama will unfold in the next moment. It soon becomes evident that Renée, has the capability to detect dead bodies and she is drawn towards death as her mother was and learning about a death which is very similar to her parents' she begins to investigate this supernatural mystery.

This novel is filled with gothic elements which is of great interest to the teenagers as they are obsessed with gothic and mystery and everything related to supernatural. Coming to the characters which the vampires have, Dante can be said to have these features which are about to be mentioned. Dante is a loner but he is not lonely. Eleanor says, "He even stopped hanging out with his friends, and now just does everything alone. He's sort of like this social outcast, except that everyone is secretly obsessed with him." In this novel, Renée is herself a teenager and she is very much attracted to Dante which is natural, being one of the criteria of the teens, that their boyfriends or girlfriends should be charming. Eleanor also says to Renée, that “... The thing is...he's beautiful. He's this rugged, devastatingly gorgeous guy who has inexplicably chosen a life of solitude. And he's brilliant. Some Latin prodigy or something. Most people here can't decide if they love him, hate him, or are scared of him."

Renée was attracted to this solitariness of Dante and every other teen girl reader would, as they themselves want in their adolescent stage to stay lonely sometimes. Though the ending of this novel is a bit sad and cliffhanging sort of, but throughout the novel it gives the teen readers those elements of mystery, passionate love, death incidents which keep them wondering of the fact that what if this magical world would have been real and they too would have got the opportunity to experience these adventures. Gore and cruelty is not present in this novel and there is also the perfect mixture of the "old" and the "new" vampires. Overall, this is a good novel; though not as famous or compact and concrete like "Twilight" or "Vampire Diaries", still it has managed to grab the attention of the teen readers as for a one time reading it will give them immense pleasure.

\section{CONCLUSION}

The whole point about this discussion raises only one question at last - that is, "so what"? So, what if the teens are so much obsessed with the vampire fiction which is nothing but fantasy? Well, from the post- "Twilight" season, the teens especially have become obsessed with the idea of vampires and werewolves and witches. They just seem to can't get enough of it. Because of their involvement in this area, they are somehow going deeper and deeper into the black hole, where there will be no Edward, or Stefan or Damon to come and save them. They are trying to imagine such a world and is getting so much obsessed with it, that it is affecting their personal and academic lives very badly. These vampire fictions are seemingly, becoming a dangerous element to the teenage girls, specially of the foreign countries, as they are more in contact with these than the Indian teens. But now, it has started spreading rapidly among the minds of the Indian teens as well, as they have also now become so much obsessed with vampire models that they are forgetting that they dwell in the reality where magic does not exist. They start expecting more from their friends, that they would give up their lives for each other if situation demands, comparing the friendship of Bonnie, Elena and Caroline. They also start expecting that their parents would be as open minded to discuss about their personal lives and let them stay at their friend's home whenever they ask, comparing the relationship between Bella and her dad. The perfect relationship like Edward and Bella cannot exist in real life and when the teens start comparing this kind of relationship to theirs, problems start cropping up and in the process their near perfect relationship suffers. Every relationship has problems and no one is perfect; if such comparisons are to be made then, no relationship would survive. This particular thing is to be properly nailed inside the minds of the teens by giving them proper guidance and parents should also be open enough to discuss things with their children and eradicate their loneliness by engaging them in various activities. Nowadays, parents have become so busy that they don't have enough time for their children and as a result of that, children are trying to find means of 
escaping to a world where they won't be alone and they will get to identify themselves with these characters, thus finding a new identity for them.

Again, it definitely can't be said that Edward Cullen or the other handsome vampires are a total bad influence on the teenagers. The fact that Bella manages both her love life as well as her studies give impetus to the children to balance their lives and academic career at a same pace. So, the effect is both good and bad on the teens and they should get the taste of these things and can escape the reality for some time but they should also not forget the reality and where they belong and with what kind of people. They should realize the fact that, relationships cannot be perfect and they will have to find perfection within the imperfections to achieve a good and healthy relationship in all sectors of life.

\section{ACKNOWLEDGEMENT}

I am very happy to acknowledge the fact that all of my professors, friends and family have given full support to me while writing this project. I would like to convey my special thanks to my professors, Dr. Paromita Mukherjee, Prof. Ranita Chakraborty Dasgupta, Prof. Sreetanwi Chakraborty and Prof. Atreya Banerjee for their constant support, help and fruitful criticisms. Technology too, has helped me a lot as apart from books most of the research work has been done with the help of internet.

\section{REFERENCES}

[1] Vranich, Dr. Belisa. (2010, July 23). Why We Love Vampires.

Retrieved

from

https://www.huffingtonpost.com/belis a-

vranich/why-we-love-vampires-the b 655674.html

[2] Morgan, Chris. (2011, February 21). Evolution of Vampire Culture. Retrieved from https://psupopculture.wordpress.com/2011/02/21evo lution-of-vampire-culture/

[3] Wilson, Gemma. (2013, March 24). Why is The Vampire Diaries So Addictive?! . Retrieved from https://www.wetpaint.com/why-is-the-vampirediaries-so-addictive-768444/

[4] My Theories about what makes Twilight so popular. (n.d.). Retrieved from www.fanpop.com/clubs/critical-analys is-oftwilight/articles/93516/title/theories-about-whatmakes-twilight-popular

[5] Ferris, Amanda. (2012, November 15). 10 Reasons Why 'The Vampire Diaries' Is Better Than 'Twilight'. Retrieved from https://thefew.com/10reasons-why-the-vampire-diaries-is-better-thantwilight/
[6] Kosolcharoen, Tiffany. (2014, February 1). Why is Twilight so popular?. Retrieved from https://www.quora.com/Why-is-Twilight-so-popular

[7] Culberston, Kieley. (2012, October 7). Evolution of the Vampire. Retrieved from https://blogs.commons.georgetown.edu/engl-090fall2012/2012/10/07/evolution-of-the-vampire/

[8] Gold, Tanya. (2009, November 13). Why have teenage girls been bitten by the Edward Cullen bug to devour the Twilight novels?. Retrieved from https://www.theguardian.com/books/2009/nov/13/tw ilight-vampires-teenage-girls

[9] Wagner, Jennifer. (2009, July 8). Why are Vampires so Popular? . Retrieved from https://connectwithyourteens.net/why-are-vampiresso-popular/

[10] Woon, Yvonne. (2011). Dead Beautiful. London: Hyperion.

[11] Guðmundsdóttir Berglind. (2015). The Vampire's Evolution in Literature : The Influence Bram Stoker's Dracula Has Had on the Works of Writers of Modern Young Adult Vampire Fiction (B.A. thesis). University of Iceland, Iceland, Europe. 